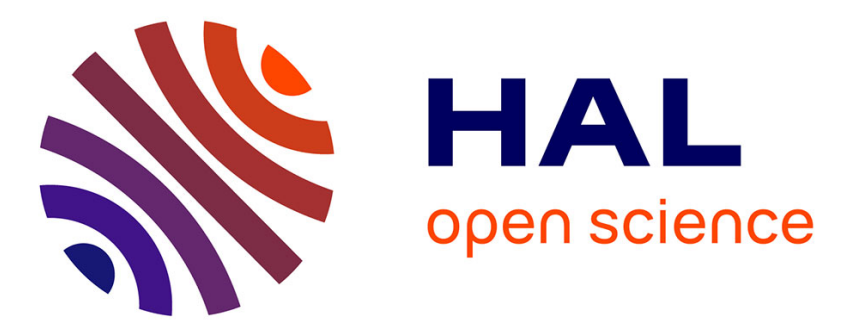

\title{
Simulated urban carbon monoxide air pollution exacerbates rat heart ischemia-reperfusion injury
}

G. Meyer, L. André, T. Sandré, J. Boissiere, C. Farah, F. Lopez-Lauri, S. Gayrard, Sylvain Richard, F. Boucher, Olivier Cazorla, et al.

\section{- To cite this version:}

G. Meyer, L. André, T. Sandré, J. Boissiere, C. Farah, et al.. Simulated urban carbon monoxide air pollution exacerbates rat heart ischemia-reperfusion injury. AJP - Heart and Circulatory Physiology, 2010, 298 (5), pp.H1445 - H1453. 10.1152/ajpheart.01194.2009 . hal-01824345

\section{HAL Id: hal-01824345 \\ https://hal.umontpellier.fr/hal-01824345}

Submitted on 13 Apr 2020

HAL is a multi-disciplinary open access archive for the deposit and dissemination of scientific research documents, whether they are published or not. The documents may come from teaching and research institutions in France or abroad, or from public or private research centers.
L'archive ouverte pluridisciplinaire HAL, est destinée au dépôt et à la diffusion de documents scientifiques de niveau recherche, publiés ou non, émanant des établissements d'enseignement et de recherche français ou étrangers, des laboratoires publics ou privés. 


\title{
Simulated urban carbon monoxide air pollution exacerbates rat heart ischemia-reperfusion injury
}

\author{
G. Meyer, ${ }^{1}$ L. André, ${ }^{2}$ S. Tanguy, ${ }^{1}$ J. Boissiere, ${ }^{2}$ C. Farah, ${ }^{1}$ F. Lopez-Lauri, ${ }^{4}$ S. Gayrard, ${ }^{1}{ }^{~ S . ~ R i c h a r d, ~}{ }^{2}$ \\ F. Boucher, ${ }^{3}$ O. Cazorla, ${ }^{2}$ P. Obert, ${ }^{1}$ and C. Reboul ${ }^{1}$ \\ ${ }^{1}$ Research Laboratory: Equipe d'Accueil 4278, Physiology and Physiopathology of Cardiovascular Adaptations to Exercise, \\ and ${ }^{4}$ Research Laboratory: Equipe d'Accueil 4279, Faculty of Sciences, Avignon University, Avignon; ${ }^{2}$ Research Laboratory: \\ Institut National de la Santé et de la Recherche Médicale Unité 637, Cardiovascular Physiopathology, Montpellier \\ University, Faculty of Medicine, Montpellier; and ${ }^{3}$ Research Laboratory: Unite Mixte de Recherche 5525 Physiologie cardio- \\ Respiratoire Expérimentale Théorique et Appliquée-Techniques de l’Ingénierie Médicale et de la Complexité, Grenoble \\ University Joseph Fourier, Grenoble, France
}

Meyer G, André L, Tanguy S, Boissiere J, Farah C, LopezLauri F, Gayrard S, Richard S, Boucher F, Cazorla O, Obert P, Reboul C. Simulated urban carbon monoxide air pollution exacerbates rat heart ischemia-reperfusion injury.

- Myocardial damages due to ischemia-reperfusion (I/R) are recognized to be the result of a complex interplay between genetic and environmental factors. Epidemiological studies suggested that, among environmental factors, carbon monoxide (CO) urban pollution can be linked to cardiac diseases and mortality. The aim of this work was to evaluate the impact of exposure to $\mathrm{CO}$ pollution on cardiac sensitivity to I/R. Regional myocardial I/R was performed on isolated perfused hearts from rats exposed for $4 \mathrm{wk}$ to air enriched with $\mathrm{CO}(30-100 \mathrm{ppm})$. Functional variables, reperfusion ventricular arrhythmias (VA) and cellular damages (infarct size, lactate dehydrogenase release) were assessed. Sarcomere length shortening and $\mathrm{Ca}^{2+}$ handling were evaluated in intact isolated cardiomyocytes during a cellular anoxia-reoxygenation protocol. The major results show that prolonged $\mathrm{CO}$ exposure worsens myocardial $\mathrm{I} / \mathrm{R}$ injuries, resulting in increased severity of postischemic VA, impaired recovery of myocardial function, and increased infarct size ( $60 \pm 5$ vs. $33 \pm 2 \%$ of ischemic zone). The aggravating effects of $\mathrm{CO}$ exposure on $\mathrm{I} / \mathrm{R}$ could be explained by a reduced myocardial enzymatic antioxidant status (superoxide dismutase $-45 \%$; glutathione peroxidase $-49 \%$ ) associated with impaired intracellular $\mathrm{Ca}^{2+}$ handling. In conclusion, our results are consistent with the idea that chronic CO pollution dramatically increases the severity of myocardial I/R injuries.

environmental pollution; myocardial infarction; antioxidant status

MYOCARDIAL DAMAGES RESULTING from ischemia-reperfusion $(\mathrm{I} / \mathrm{R})$ are a major cause of morbidity and mortality in western nations. Those myocardial I/R injuries result in cardiac dysfunction, arrhythmias, as well as irreversible myocyte damages $(25,28)$. The sensitivity of the myocardium to I/R-induced cellular injuries is recognized today to be the result of a complex interplay between genetic, pathological, and environmental factors. Moreover, it appears to be aggravated in several diseases, including hypertension, metabolic disorders, and complications from cigarette smoking and environmental pollution.

Address for reprint requests and other correspondence: C. Reboul, Research Laboratory: EA 4278, Physiology and Physiopathology of Cardiovascular Adaptations to Exercise, Faculty of Sciences, Avignon Univ., F-84000 Avignon, France (e-mail: Cyril.reboul@univ-avignon.fr).
Among the environmental factors that could influence the development of cardiovascular diseases, several epidemiological studies have recently suggested that urban atmospheric pollution may exert adverse effects on cardiovascular health (7, $11,12,15)$. Among the numerous pollutants, carbon monoxide (CO) has been described as one of the main pollutants responsible for the development of cardiovascular diseases $(9,35)$. In urban environments, $\mathrm{CO}$ concentration usually varies from 2 to $40 \mathrm{ppm}$, but during heavy traffic it may be as high as $170 \mathrm{ppm}$ $(10,34,40)$. At this level, $\mathrm{CO}$ exposure has been correlated with hospital admissions, mortality, and morbidity related to cardiovascular diseases $(9,13,29)$. Today, although the pathophysiological mechanisms regarding acute $\mathrm{CO}$ poisoning are well known, mechanisms associated with chronic exposure to lower concentrations of $\mathrm{CO}$, consistent with urban environmental pollution, remain unclear. We (2) and Bye et al. (14) have recently reported that prolonged $\mathrm{CO}$ exposure induces a pathological myocardial cellular phenotype characterized by a major remodeling of the excitation-contraction coupling. Such deleterious consequences may worsen the effect of cardiovascular diseases.

The aim of this experimental work was to challenge the impact of a chronic exposure to simulated $\mathrm{CO}$ urban pollution on the sensitivity of the myocardium to $\mathrm{I} / \mathrm{R}$ in a rat model. The major result shows that prolonged exposure to $\mathrm{CO}$ at a level found in the urban environment has a dramatic deleterious impact on the sensitivity of the myocardium to $\mathrm{I} / \mathrm{R}$.

\section{METHODS}

Experiments complied with the Guide for the Care and Use of Laboratory Animals published by the United States National Institutes of Health (National Institutes of Health Publications no. 85-23, revised 1996) and was approved by the French Ministry of Agriculture.

Animals and CO Exposure

Adult, male Wistar rats $(n=64 ; 345 \pm 7$ g; Charles River Laboratories) were randomly assigned to the following two groups: $\mathrm{CO}$ rats (exposed for $4 \mathrm{wk}$ to simulated $\mathrm{CO}$ urban pollution, $n=32$ ) and control animals (Ctrl rats, exposed to standard filtered air, $n=$ 32). $\mathrm{CO}$ rats were housed in an airtight exposure container for $4 \mathrm{wk}$. Exposure was performed according to a 12:12-h CO in the air-ambient air cycle. To simulate $\mathrm{CO}$ urban pollution, exposure was performed as follows: during $\mathrm{CO}$ exposure, a $\mathrm{CO}$ concentration of $30 \mathrm{ppm}$ was maintained in the airtight container and monitored with an aspirative CO analyzer (CHEMGARD Infrared Gas Monitor NEMA 4 Version 
MSA). This initial concentration was supplemented with five 1-h peaks at $100 \mathrm{ppm}$ CO. During ambient air exposure, animals were placed in the laboratory animal house with a $\mathrm{CO}$ concentration of 0 $\mathrm{ppm}$. Ctrl rats were confined in the laboratory animal house for $4 \mathrm{wk}$ and were manipulated daily. At the end of the 4-wk CO exposure, rats were housed $24 \mathrm{~h}$ in standard filtered air to avoid the acute effects of $\mathrm{CO}$ on the myocardium.

\section{Regional Myocardial Ischemia and Reperfusion on Isolated Perfused Rat Heart}

Rats were anaesthetized with pentobarbital sodium ( $50 \mathrm{mg} / \mathrm{kg}$ ip). A thoracotomy was performed, and the heart was rapidly removed, by cutting the great vessels, and immersed in ice-cold Krebs solution. The heart was transferred to the perfusion apparatus, and the aorta was cannulated for perfusion with oxygenated $\left(95 \% \mathrm{O}_{2}-5 \% \mathrm{CO}_{2}\right)$ Krebs solution $\left(37^{\circ} \mathrm{C}\right.$ ) composed of (in $\left.\mathrm{mM}\right) 118.3 \mathrm{NaCl}, 25 \mathrm{NaHCO}_{3}, 4.7$ $\mathrm{KCl}, 1.2 \mathrm{MgSO}_{4}, 1.2 \mathrm{KH}_{2} \mathrm{PO}_{4}, 11.1$ glucose, and $2.5 \mathrm{CaCl}(\mathrm{pH}=$ 7.4). The hearts were perfused at a constant pressure $(80 \mathrm{mmHg})$.

Evaluation of postischemic reperfusion injury. On a first set of rats ( $n=8$ /group), the atrioventricular node was crushed using fine forceps, the right atrium was excised, and the hearts were paced at a rate of 300 beats/min with an electrical stimulator (low voltage stimulator, BSL MP35 SS58L, 3V). An ultrathin, water-filled balloon was inserted in the left ventricle via the mitral valve, and the balloon volume was adjusted to achieve a left ventricular (LV) end diastolic pressure of $5 \mathrm{mmHg}$. Coronary blood flow was measured by collection of the infiltration effluents. A suture on a round-bodied needle was placed around the left anterior descending coronary artery (LAD), and the suture ends were placed around a small length of tubing to form a snare. The heart was allowed to stabilize for $30 \mathrm{~min}$. Following the stabilization period, the LAD was occluded for $30 \mathrm{~min}$. Subsequently, the snare occluder was released to allow reperfusion of the previously ischemic vascular bed for $120 \mathrm{~min}$. The LAD was then reoccluded, and Evans blue dye solution $(5 \mathrm{ml}, 2 \%)$ was injected in the left ventricle to allow perfused (stained blue) and nonperfused (unstained) areas of the heart to be distinguished. After removal of the hearts, it was divided into five slices perpendicular to the apex-base axis. Triphenyltetrazolium chloride staining $(0.5 \mathrm{mg} / \mathrm{ml}$ for $20 \mathrm{~min}$ at $37^{\circ} \mathrm{C}$ ) was used to assess myocardial tissue viability and to determine myocardial infarct size. Tissue slices were photographed, and area at risk and infarcted area were then determined using a computer-based system (ImageJ; NIH).

Evaluation of postischemic reperfusion-induced ventricular arrhythmias. On a second set of rats ( $n=14$ /group), arrhythmic events were evaluated on isolated nonpaced hearts. The heart was mounted, and the LAD occlusion was performed as previously described. A computerized electrocardiogram was obtained continuously during the protocol. The various types of arrhythmias were defined as described in the Lambeth conventions (39). The analysis of the electrocardiogram enabled assessment of the incidence (percent no. of hearts exhibiting a given type of arrhythmia) of different types of ventricular arrhythmias (Fig. 1A) as follows: sinus rhythm, ventricular premature beats (VPB), ventricular tachycardia (VT), and ventricular fibrillation (VF). To allow the comparison of the severity of rhythm disturbances occurring upon reperfusion, each individual heart was characterized according to a five-point arrhythmic score previously described by Tanguy et al. (37) and designed so that the more severe the arrhythmia, the larger the number (Fig. 1B). Such a simplified scoring system allows the assignment of a single number to each heart, and the comparison of the distribution of the hearts by various scores.

\section{Cardiomyocyte Excitation-Contraction Analysis After Cellular Anoxia-Reoxygenation}

On a third set of rats ( $n=4$ /group), single ventricular cardiomyocytes were isolated by enzymatic digestion as previously described (24). Cardiomyocytes were transferred to a glass petri dish and placed in an anoxic chamber $\left(\mathrm{O}_{2}\right.$ level $\left.\sim 2 \%\right)$ for $60 \mathrm{~min}$, followed by a 60 -min reoxygenation in ambient air $\left(\mathrm{O}_{2} \sim 19.4 \%\right)$. Unloaded cell shortening and $\mathrm{Ca}^{2+}$ concentration (indo 1 dye) were measured using field stimulation $\left(0.5 \mathrm{~Hz}, 22^{\circ} \mathrm{C}, 1.8 \mathrm{mM}\right.$ external $\left.\mathrm{Ca}^{2+}\right)$ before and after anoxia-reoxygenation (A/R). Sarcomere length (SL) and fluorescence (405 and $480 \mathrm{~nm}$ ) were recorded simultaneously (IonOptix system; Hilton). The A/R experiment was then carried out in the presence or absence of a nonspecific antioxidant [ $N$-acetylcystein (NAC), $20 \mu \mathrm{M}$ ].

\section{Biochemical Assays}

Heart antioxidant enzyme activity. A fourth set of rats $(n=$ 6/group) was used to evaluate the enzymatic antioxidant status of the myocardium consecutive to chronic $\mathrm{CO}$ exposure and before I/R After the end of $\mathrm{CO}$ exposure ( $24 \mathrm{~h}$ ), the hearts were freeze-clamped, and the frozen ventricular tissue was homogenized in Tris. $\mathrm{HCl}$ buffer (60 $\mathrm{mM}$ Tris $\cdot \mathrm{HCl}$ and $1 \mathrm{mM}$ diethyltriaminopentaacetic acid, $\mathrm{pH}$ 7.4, $10 \mathrm{ml} / \mathrm{g}$ wet wt) using a Teflon potter homogenizer. Tissue homogenates were then centrifuged for $10 \mathrm{~min}$ at $200 \mathrm{~g}$ at $4^{\circ} \mathrm{C}$ to remove all nuclear debris. Cardiac superoxide dismutase (SOD) activity was assessed in the supernatant according to the method described by Marklund (22). Cardiac glutathione peroxidase (GPx) activity was assessed spectrophotometrically on the cytosolic fraction according to the method described by Flohe and Günzler (18). Catalase activity was determined according to the method described by Beers and Sizer (8). All enzyme activities were expressed in units per milligram protein (U/mg protein). The modified method of Lowry et al. (21) was used to determine protein content of tissue homogenates, using BSA as standard.

Lactate dehydrogenase in coronary effluents. Lactate dehydrogenase (LDH) activity was measured in coronary effluents by spectrophotometry using an LDH kit (LDH-P; BIOLABO). Measurements were made at the end of stabilization and at 10,30, and 60 min of reperfusion. $\mathrm{LDH}$ activity was normalized to coronary blood flow.

Thiobarbituric acid-reactive substances in LV tissues. Thiobarbituric acid-reactive substances (TBARS) were assessed in LV tissues after $30 \mathrm{~min}$ of reperfusion using the thiobarbituric acid (TBA) test. Frozen heart tissue $(120 \mathrm{mg})$ was homogenized in $1 \mathrm{ml} 0.1 \%$ TCA solution. The homogenate was centrifuged at $12,000 \mathrm{~g}$ for $15 \mathrm{~min}$, and $0.5 \mathrm{ml}$ of the supernatant was added to $1 \mathrm{ml}$ of $0.5 \%$ TBA in $20 \%$ TCA. The mixture was incubated in boiling water for $30 \mathrm{~min}$, and the reaction was stopped by placing the reaction tubes in an ice bath. Tubes were briefly vortexed, triplicate $200-\mu l$ aliquots were taken from each tube and placed in 96-well plates, and the supernatant absorbance was read at $532 \mathrm{~nm}$ in a microplate reader. The value for nonspecific absorption at $600 \mathrm{~nm}$ was subtracted. The amount of TBARS (red pigment) was calculated using an extinction coefficient of $155 \mathrm{mM}^{-1} \cdot \mathrm{cm}^{-1}$.

\section{Statistics}

Data were analyzed using one-way ANOVA between groups and repeated-measures ANOVA when necessary. When significant interactions were found, a Tukey-Kramer test was applied. The distribution of the hearts based on the various arrhythmic scores was analyzed by a nonparametric Mann-Whitney $U$-test. Binomially distributed variables (such as incidence of VF) were analyzed using nonparametric Yates' chi square test (Statview; Adept Scientific, Letchworth, UK). A level of $P<$ 0.05 was considered statistically significant. Data are expressed as group means or group mean fractions of baseline $\pm \mathrm{SE}$.

\section{RESULTS}

\section{Effects of CO Exposure on Myocardial Reperfusion Ventricular Arrhythmias}

The time course of reperfusion-induced VPB, VT, and VF in individual hearts is shown in Fig. $1 C$. Figure $1 D$ shows a 
A

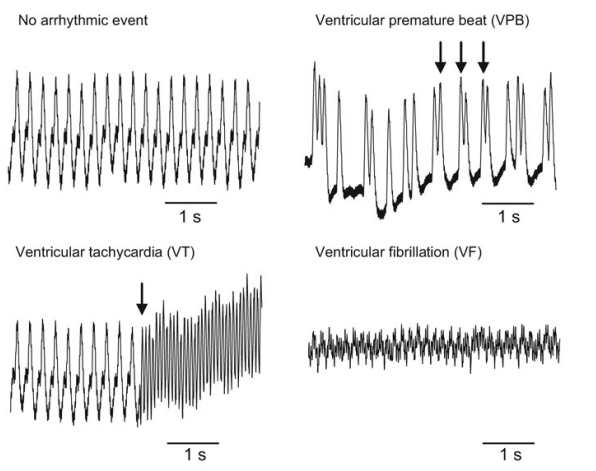

C

Ctrl Rats $(\mathrm{n}=11)$

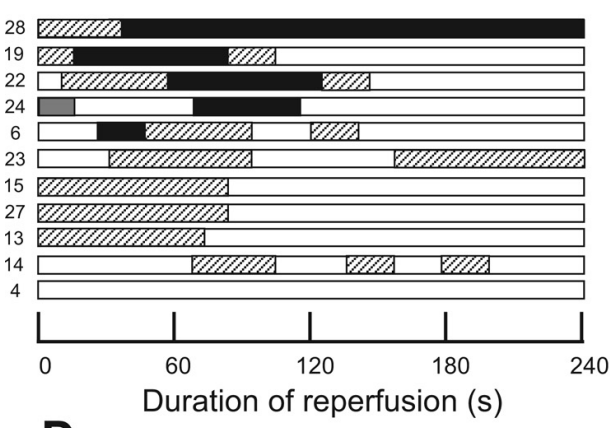

D

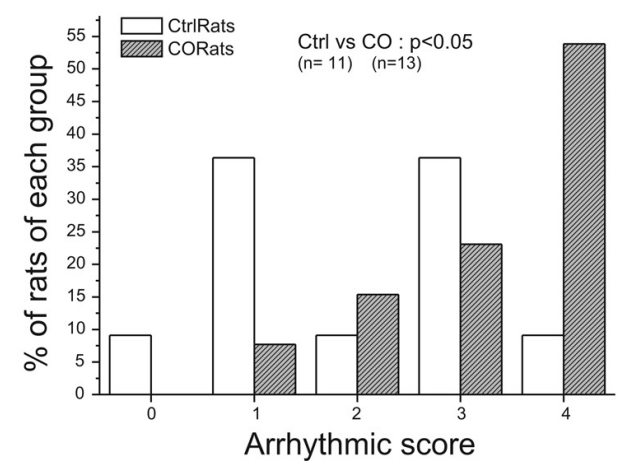

B

\begin{tabular}{ll} 
Arrhythmic score in the setting of acute $M I$ \\
\hline Score & Event \\
0 & No arrhythmic event \\
1 & Only VPB \\
2 & VT with or without VPB \\
3 & Reversible VF \\
4 & Sustained VF \\
\hline
\end{tabular}

Fig. 1. Effects of carbon monoxide (CO) exposure on the severity of postischemic reperfusion-induced arrhythmic events. Electrocardiographic recordings $(A)$ of normal sinus rhythm and of arrhythmias identified during postischemic reperfusion as described in the Lambeth Convention [sinus rhythm, ventricular premature beat (VPB), ventricular tachycardia (VT), and ventricular fibrillation (VF)] and related arrhythmic scores $(B)$. $C$ : time course of reperfusion-induced VPB (crossed out bars), VT (gray bars), and VF (black bars) of each heart of the control (Ctrl) group (left) and CO (right) group (nos. on left refer to the order of the experiments). $D$ : categorization of arrhythmia classes (score) according to $B$. Values are expressed as a percentage of the total no. of hearts for each group (Ctrl rats $n=11, \mathrm{CO}$ rats $n=$ 13 , distribution was tested using nonparametric Mann-Whitney's test, Ctrl vs. CO rats: $P<$ $0.05)$. MI, myocardial infarction. $E$ : effects of $\mathrm{CO}$ exposure on mean arrhythmic score (data are presented as means $\pm \mathrm{SE}, \mathrm{Ctrl}$ rats $n=11$, CO rats $n=13$, one-way ANOVA, $* P<0.05$, Ctrl vs. CO rats).

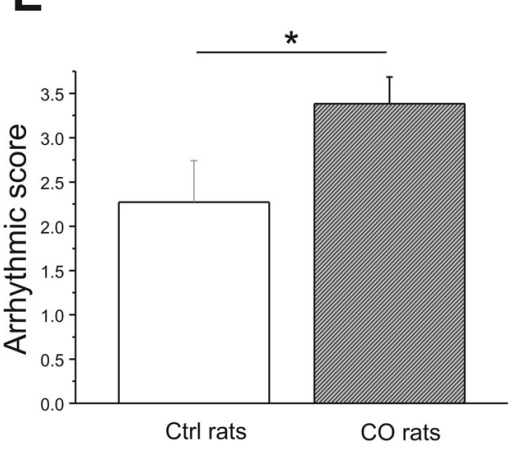

significant difference in the distribution of the arrhythmic scores observed in both experimental groups. According to the increased mean arrhythmic score observed in $\mathrm{CO}$ rats during reperfusion, the arrhythmia severity was higher in $\mathrm{CO}$ rats compared with Ctrl rats (Fig. 1E). Moreover, sustained VF were triggered more frequently in the $\mathrm{CO}$ rats compared with Ctrl rats (54 vs. 9\%, $P<0.05$ nonparametric Yates' chi square test).

\section{Effects of CO Exposure on Postischemic Recovery of Myocardial Function}

Any difference regarding cardiac function was reported between $\mathrm{CO}$ and $\mathrm{Ctrl}$ rats before ischemia (Table 1). Postischemic recovery of $\mathrm{LV}$ developed pressure and contractility, assessed during reperfusion, was significantly lower in CO rats compared with Ctrl (Fig. 2). Indeed, the postischemic recovery of $\mathrm{LV}$ developed pressure, $+\mathrm{dP} / \mathrm{d} t_{\max }$, and $-\mathrm{dP} / \mathrm{d} t_{\max }$ were significantly altered in the $\mathrm{CO}$ rats compared with $\mathrm{Ctrl}$ rats (Fig. 2, A-C).

These functional results were paired with some deleterious effects of $\mathrm{CO}$ exposure on postischemic myocardial coronary blood flow recovery (Fig. 2D). Indeed, although no difference in coronary blood flow was reported between $\mathrm{CO}$ and Ctrl rats before ischemia (Ctrl rats: $11.5 \pm 0.9 \mathrm{ml} / \mathrm{min}$ vs. CO rats: $11.8 \pm 1.4 \mathrm{ml} / \mathrm{min})$, coronary blood flow was significantly lower in $\mathrm{CO}$ rats compared with $\mathrm{Ctrl}$ rats during reperfusion.

\section{Effects of CO Exposure on Myocardial Postischemic Reperfusion-Induced Cellular Death}

The deleterious effects of $\mathrm{CO}$ exposure on I/R-induced injury were characterized by an increase in myocardial infarct 
Table 1. Myocardial function during regional ischemia-reperfusion protocol in $\mathrm{Ctrl}$ and $\mathrm{CO}$ rats

\begin{tabular}{|c|c|c|c|}
\hline & LVDP, $\mathrm{mmHg}$ & $\begin{array}{c}+\mathrm{dP} / \mathrm{d} t_{\max } \\
\mathrm{mmHg} / \mathrm{s}\end{array}$ & $\begin{array}{c}-\mathrm{dP} / \mathrm{d} t_{\max }, \\
\mathrm{mmHg} / \mathrm{s}\end{array}$ \\
\hline \multicolumn{4}{|l|}{ Baseline } \\
\hline Ctrl rats & $91.79 \pm 7.47$ & $3,365 \pm 304$ & $-1,944 \pm 123$ \\
\hline $\mathrm{CO}$ rats & $93.85 \pm 12.11$ & $2,932 \pm 369$ & $-1,994 \pm 219$ \\
\hline \multicolumn{4}{|c|}{$30 \mathrm{~min}$ of Ischemia } \\
\hline Ctrl rats & $65.50 \pm 4.82$ & $2,304 \pm 487$ & $-1,447 \pm 199$ \\
\hline $\mathrm{CO}$ rats & $53.29 \pm 5.66$ & $1,757 \pm 240$ & $-1,111 \pm 162$ \\
\hline \multicolumn{4}{|c|}{5 min of Reperfusion } \\
\hline Ctrl rats & $61.28 \pm 3.05$ & $2,169 \pm 318$ & $-1,255 \pm 103$ \\
\hline $\mathrm{CO}$ rats & $41.86 \pm 3.61^{*}$ & $1,372 \pm 276^{*}$ & $-902 \pm 131^{*}$ \\
\hline \multicolumn{4}{|c|}{30 min of Reperfusion } \\
\hline Ctrl rats & $63.31 \pm 5.15$ & $2,376 \pm 331$ & $-1,344 \pm 114$ \\
\hline $\mathrm{CO}$ rats & $43.71 \pm 5.66^{*}$ & $1,541 \pm 364 *$ & $-887 \pm 216^{*}$ \\
\hline \multicolumn{4}{|c|}{60 min of Reperfusion } \\
\hline Ctrl rats & $50.99 \pm 1.85$ & $1,996 \pm 320$ & $-1,063 \pm 81$ \\
\hline $\mathrm{CO}$ rats & $36.10 \pm 6.62 *$ & $1,332 \pm 365$ & $-761 \pm 115^{*}$ \\
\hline \multicolumn{4}{|c|}{90 min of Reperfusion } \\
\hline Ctrl rats & $43.54 \pm 1.33$ & $1,747 \pm 376$ & $-920 \pm 120$ \\
\hline $\mathrm{CO}$ rats & $31.78 \pm 9.76$ & $1,203 \pm 331$ & $-703 \pm 121$ \\
\hline \multicolumn{4}{|c|}{120 min of Reperfusion } \\
\hline Ctrl rats & $39.85 \pm 2.52$ & $1,609 \pm 258$ & $-832 \pm 110$ \\
\hline $\mathrm{CO}$ rats & $24.52 \pm 5.91 *$ & $1,028 \pm 237 *$ & $-570 \pm 169^{*}$ \\
\hline
\end{tabular}

Values are means $\pm \mathrm{SE}$; LVDP, left ventricular developed pressure; $+\mathrm{dP} /$ $\mathrm{d} t_{\max }$, maximal derivative of left ventricular pressure; $-\mathrm{dP} / \mathrm{d} t_{\min }$, minimal derivative of left ventricular pressure; Ctrl rats, rats exposed to filtered standard air; $\mathrm{CO}$ rats, rats exposed to carbon monoxide. ${ }^{*} P<0.05$ vs. Ctrl rats.

size in $\mathrm{CO}$ rats compared with $\mathrm{Ctrl}$ rats (Fig. 3, $A$ and $B$ ). Indeed, no difference regarding the risk zone (ischemic zone) was observed between $\mathrm{CO}$ and Ctrl rats after $120 \mathrm{~min}$ of reperfusion. However, the infarct size was markedly increased in $\mathrm{CO}$ rats $(60 \pm 5$ vs. $33 \pm 2 \%$ of the risk zone; $P<0.05)$. LDH released in coronary effluents, used as an index of cell death, was significantly augmented at the onset of reperfusion in both Ctrl and CO rats $(1.91 \pm 0.30$ to $5.84 \pm 1.45 \mathrm{U} / \mathrm{min}$ for Ctrl rats; $2.69 \pm 0.54$ to $14.26 \pm 3.20 \mathrm{U} / \mathrm{min}$ for $\mathrm{CO}$ rats; $P<$ 0.05). Moreover, the peak of $\mathrm{LDH}$ release at the onset of reperfusion was significantly higher in $\mathrm{CO}$ rats than in Ctrl rats. Finally, $\mathrm{LDH}$ release remained significantly higher in $\mathrm{CO}$ rats after 30 and $60 \mathrm{~min}$ of reperfusion. No difference regarding $\mathrm{LDH}$ release was observed during the stabilization period (Fig. $3 C$ ). LV TBARS concentration was significantly increased in $\mathrm{CO}$ compared with $\mathrm{Ctrl}$ rats after $30 \mathrm{~min}$ of reperfusion $(6.43 \pm 0.76$ vs. $4.40 \pm 0.35 \mathrm{nmol} / \mathrm{g}$; Fig. $3 D)$.

\section{Effects of CO Exposure on Cardiomyocyte \\ Excitation-Contraction Coupling Before and After A/R}

At the cellular level, prolonged $\mathrm{CO}$ exposure induced impairments of ventricular myocyte function (Fig. 4). Indeed, before A/R, SL shortening (Fig. 4, $A$ and $B$ ) as well as $\mathrm{Ca}^{2+}$ transient (Fig. 4, $C$ and $D$ ) were significantly impaired in $\mathrm{CO}$ rats compared with $\mathrm{Ctrl}$ rats. In addition, diastolic cytosolic $\mathrm{Ca}^{2+}$ was markedly higher in $\mathrm{CO}$ compared with Ctrl rats (Fig. $4 E$ ). Consecutively to $\mathrm{A} / \mathrm{R}$, SL shortening was decreased in both groups (Fig. 4, $A$ and $B$ ) and remained significantly lower in CO compared with Ctrl rats. This decreased SL shortening was associated with a decreased $\mathrm{Ca}^{2+}$ transient in both groups consecutive to $\mathrm{A} / \mathrm{R}$. It is of note that $\mathrm{Ca}^{2+}$ transient from $\mathrm{CO}$ rats remained lower than $\mathrm{Ca}^{2+}$ transient from Ctrl rats (Fig. 4, $C$ and $D$ ). Following $\mathrm{A} / \mathrm{R}$, diastolic $\mathrm{Ca}^{2+}$ increased in the two experimental groups; however, for this parameter, statistical significance was reported only in Ctrl rats. Consequently,
Fig. 2. Effects of $\mathrm{CO}$ exposure on the time course of changes in left ventricular function parameters during a 30-min ischemia and 120 $\mathrm{min}$ of reperfusion. Change in left ventricle developed pressure $(A)$, maximal $\left(+\mathrm{dP} / \mathrm{d} t_{\max }\right.$ $B)$, and minimal $\left(-\mathrm{dP} / \mathrm{d} t_{\max }, C\right)$ derivative of left ventricular pressure over time, and coronary blood flow $(D)$. Data are presented as mean fraction of baseline $\pm \mathrm{SE}(n=6$ rats $/$ group, repeated-measures ANOVA, $* P<$ 0.05 , Ctrl vs. CO rats)
A

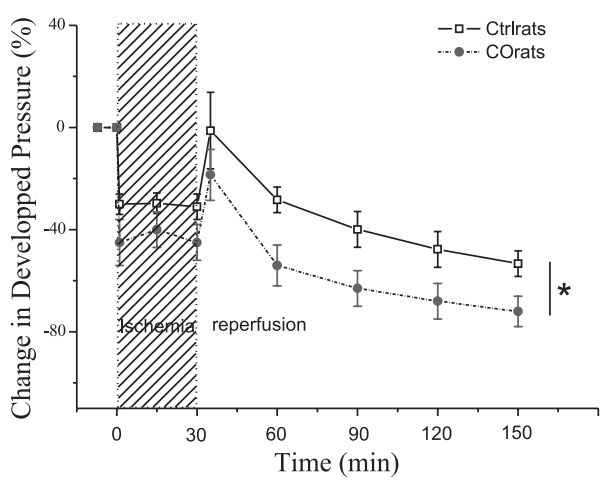

C

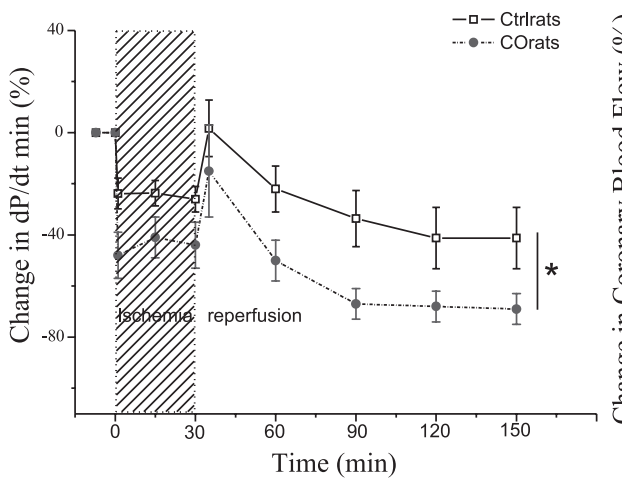

B

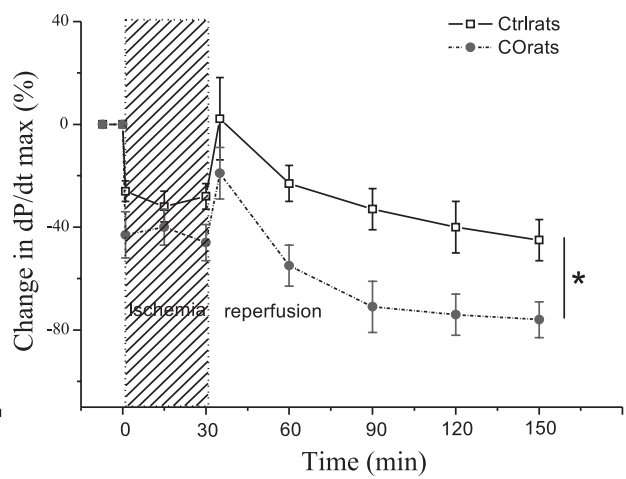

D

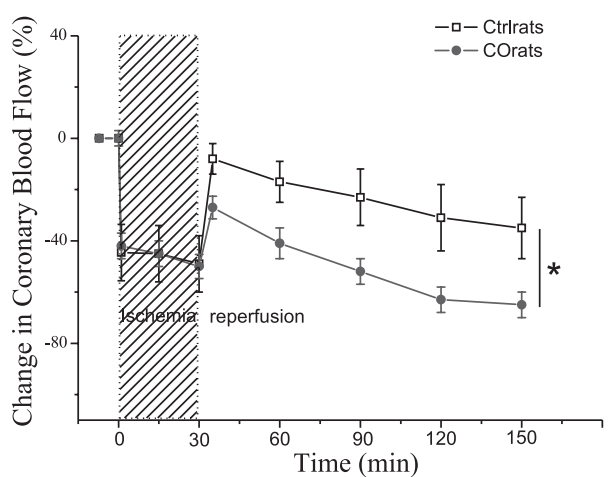




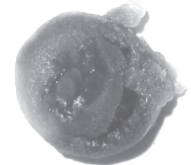

Ctrl rats

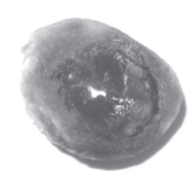

CO rats
B

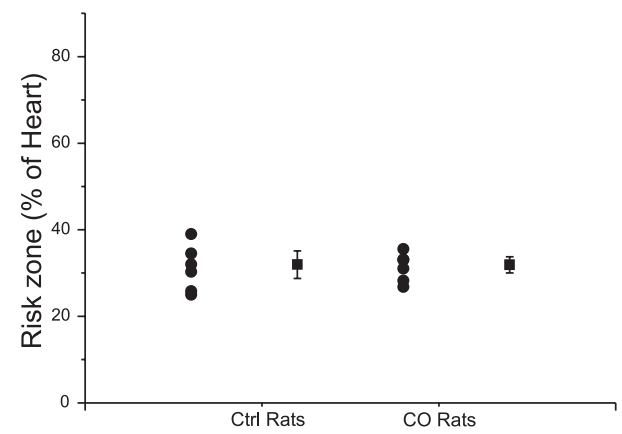

C

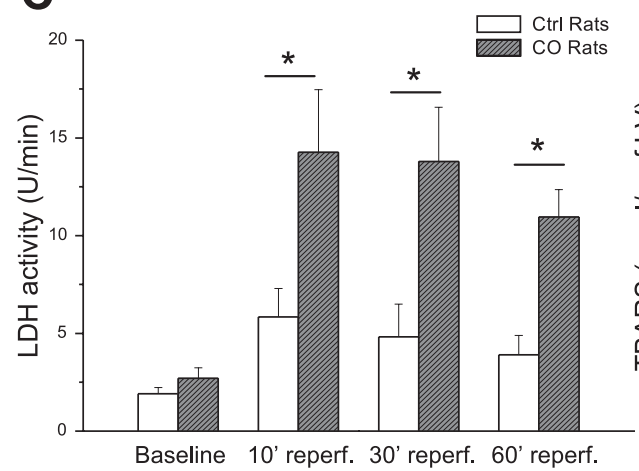

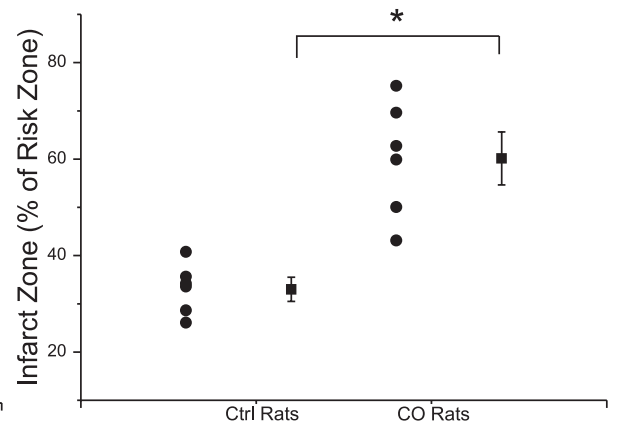

D

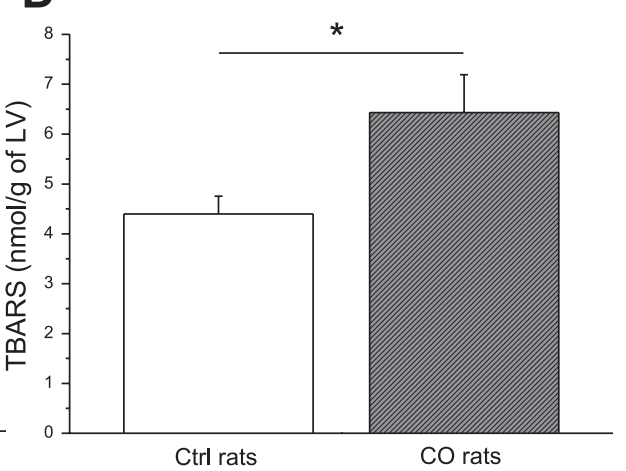

Fig. 3. Effects of $\mathrm{CO}$ exposure on I/R-induced cellular death. A: representative sections of rat hearts stained with triphenyltetrazolium chloride (TTC) after a regional ischemia of 30 and $120 \mathrm{~min}$ reperfusion from the isolated heart experiments in $\mathrm{Ctrl}$ and $\mathrm{CO}$ rats. $B$ : risk zone expressed as a percentage of heart area (left) and infarct zone expressed as a percentage of risk zone (right) Data are presented as means $\pm \mathrm{SE}(n=6$ /group, one-way ANOVA, $* P<0.05$, Ctrl vs. CO rats). $C$ : lactate dehydrogenase $(\mathrm{LDH})$ release in coronary effluents during stabilization and reperfusion, and used as a marker of cell death. $D$ : thiobarbituric acid-reactive substances (TBARS) concentration in left ventricular (LV) tissues after 30 min of postischemic reperfusion, and used as a marker of lipid peroxidation. Data are presented as means $\pm \mathrm{SE}(n=6$ rats/group, repeatedmeasures ANOVA, $* P<0.05$, Ctrl vs. CO rats). following $\mathrm{A} / \mathrm{R}$, no difference was observed concerning intracellular diastolic $\mathrm{Ca}^{2+}$ between $\mathrm{Ctrl}$ and $\mathrm{CO}$ rats (Fig. 4E).

Following $\mathrm{A} / \mathrm{R}$, the incubation of NAC (a nonspecific antioxidant) reduced the impairment of cardiac cell contraction in both $\mathrm{Ctrl}$ and $\mathrm{CO}$ rats. In addition, NAC infusion partly blunted the higher sensitivity of $\mathrm{CO}$ rat cardiomyocytes to $\mathrm{A} / \mathrm{R}$, since in this condition no difference was reported between Ctrl and $\mathrm{CO}$ groups regarding SL shortening (Fig. 5A). As far as the alterations of $\mathrm{Ca}^{2+}$ handling are concerned, the incubation of NAC improved $\mathrm{Ca}^{2+}$ transient in both $\mathrm{Ctrl}$ and $\mathrm{CO}$ rats. However, the difference between the two experimental populations was still reported (Fig. 5B). Finally, diastolic cytosolic $\mathrm{Ca}^{2+}$ was significantly reduced in $\mathrm{CO}$ rat cardiomyocytes in the presence of NAC compared with the corresponding controls (Fig. $5 C$ ). In the presence of NAC, no difference was reported regarding this variable between $\mathrm{Ctrl}$ and $\mathrm{CO}$ rats.

\section{Effects of CO Exposure on Myocardial Antioxidant Enzyme Activity}

In $\mathrm{CO}$ rats, following $4 \mathrm{wk}$ of exposure to simulated urban CO pollution, cardiac SOD and GPx activities were significantly lower compared with Ctrl rats (Fig. 6, $A$ and $B$ ). No significant change in catalase activity was observed in this model of $\mathrm{CO}$ exposure (Fig. 6C).

\section{DISCUSSION}

To the best of our knowledge, our study is the first to investigate the effects of prolonged exposure to simulated urban environmental $\mathrm{CO}$ pollution on myocardial sensitivity to $\mathrm{I} / \mathrm{R}$. The major result is that prolonged exposure to simulated urban $\mathrm{CO}$ pollution worsens myocardial I/R injuries, promoting a major increase in the severity of arrhythmic events, an impairment of myocardial function observed at both global and cellular levels, and an increase in the infarct size. These phenomena could be mainly related to hidden effects of $\mathrm{CO}$ exposure on myocardial phenotype, including 1) an impairment of cellular $\mathrm{Ca}^{2+}$ handling and 2) an altered antioxidant status of the myocardium.

\section{CO Exposure and Myocardial I/R}

Eventhough $\mathrm{CO}$ urban pollution has been associated with increased cardiovascular disease and cardiac mortality $(9,13$, 29), we demonstrate here that chronic $\mathrm{CO}$ exposure renders the heart more vulnerable to I/R. Previous experimental studies have only documented the effect of acute $\mathrm{CO}$ exposure or to CO-releasing molecules used as preconditioning strategies to protect the myocardium against I/R injury $(3,6,19)$. It was also reported that endogenous $\mathrm{CO}$ production could protect the heart from I/R injuries. These beneficial effects of endogenous 
A

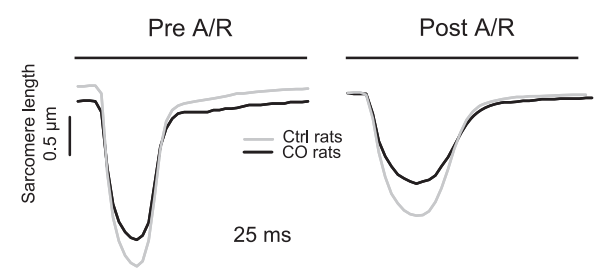

C

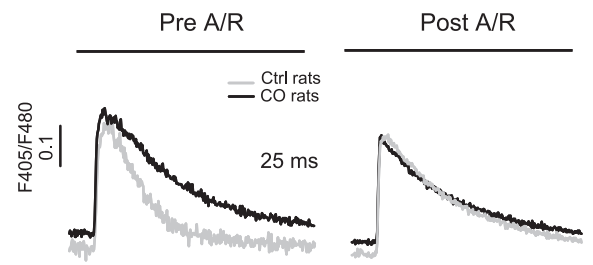

D

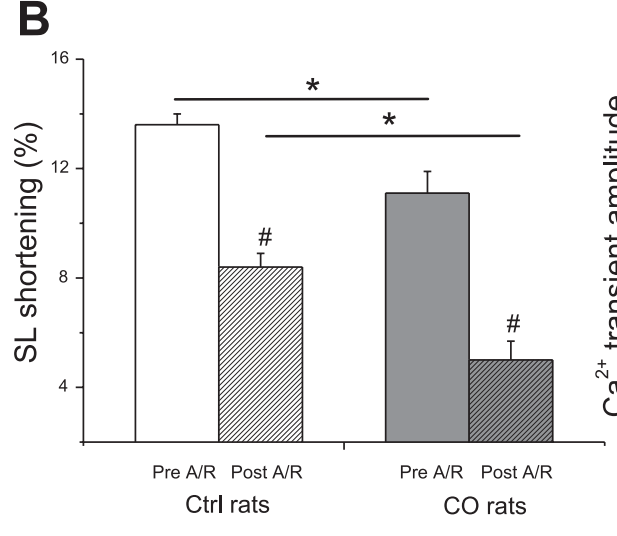

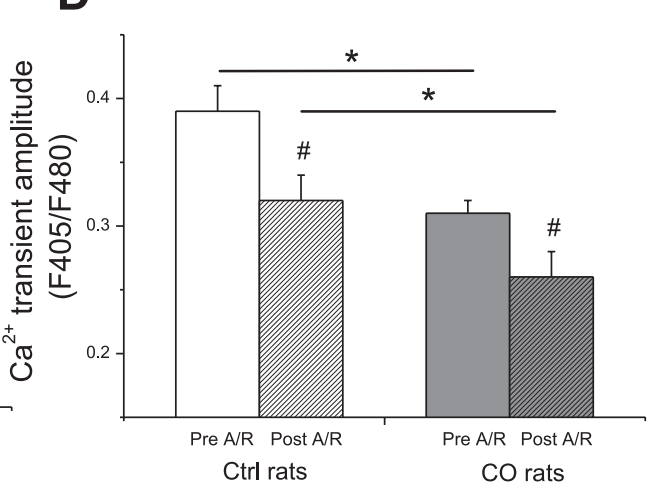

Fig. 4. Effects of $\mathrm{CO}$ exposure on cardiomyocyte excitation-contraction before and after cellular anoxia-reoxygenation (A/R). $A$ : representative contraction of intact myocytes. $B$ : contraction of intact myocytes, measured by sarcomere length (SL) shortening. SL shortening is presented as a mean of the percentage of shortening $\pm \mathrm{SE}[n=4$ rats/group, 2-way ANOVA; $P<0.05$, pre-A/R vs. post-A/R (\#) and $\mathrm{Ctrl}$ vs. $\mathrm{CO}$ rats $(*)]$. $C$ : representative superimposed $\mathrm{Ca}^{2+}$ transients in intact myocytes. $\mathrm{Ca}^{2+}$ transients $(D)$ and diastolic $\mathrm{Ca}^{2+}$ $(E)$ in intact myocytes. $\mathrm{Ca}^{2+}$ transients and diastolic $\mathrm{Ca}^{2+}$ are presented as means $\pm \mathrm{SE}$ $[n=4$ rats/group, 2-way ANOVA; $P<0.05$, pre-A/R vs. post-A/R (\#) and Ctrl vs. $\mathrm{CO}$ rats (*)]. NS, not significant.

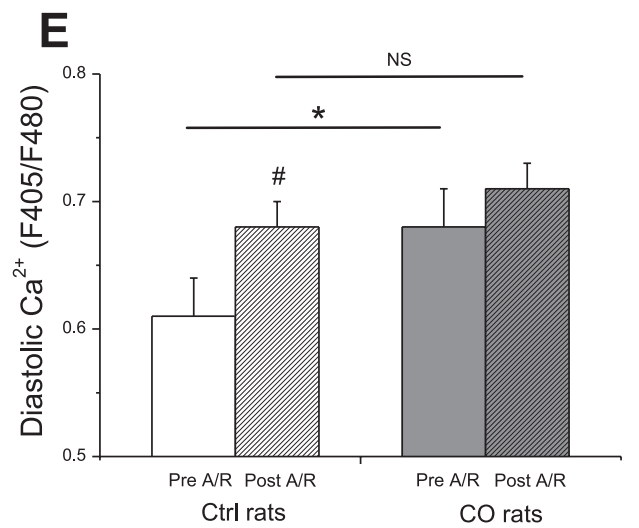

$\mathrm{CO}$ production during $\mathrm{I} / \mathrm{R}$ could be because of a decrease in oxidative stress (26), an enhanced $\mathrm{Ca}^{2+}$ handling (36), and $\mathrm{CO}$ anti-inflammatory and anti-apoptotic properties (20), which may ultimately lead to a decrease in I/R-induced VF $(4,5)$. In our model, no difference regarding cardiac function and coronary blood flow was evidenced between $\mathrm{Ctrl}$ and $\mathrm{CO}$ rats before I/R. Remarkably, only postischemic reperfusion allowed us to distinguish the hearts of $\mathrm{CO}$-exposed rats from those of Ctrl rats, thereby pointing out the deleterious effect of $\mathrm{CO}$. These results are in line with our previous study (2), which exhibited no difference of cardiac function in the basal condition but highlighted functional impairments in $\mathrm{CO}$ rats in stressful conditions (i.e., $\beta$-adrenergic stimulation). Therefore, discrepancies between our results and studies reporting the protective role of $\mathrm{CO}$ exposure could be explained by differences in the duration and severity of $\mathrm{CO}$ exposure $(3,6,19)$. In our model, $\mathrm{CO}$ rats experimented a chronic (4 wk with $12 \mathrm{~h}$ daily exposure) $\mathrm{CO}$ exposure mimicking urban concentrations (30-100 ppm). In addition, it has to be noted that, in our model, to avoid the acute effects of $\mathrm{CO}$ on the myocardium, rats were housed for $24 \mathrm{~h}$ in standard filtered air before I/R study. Therefore, under our experimental conditions, no difference of carboxyhemoglobin was made obvious between Ctrl and $\mathrm{CO}$ rats at the time of the I/R procedure (carboxyhemoglobin $24 \mathrm{~h}$ after exposure, $\mathrm{CO}$ rats: $1.2 \pm 0.4 \%$ vs. Ctrl rats $1.0 \pm 0.5 \%$; not significant).

\section{Effects of CO Exposure on Postischemic Myocardial Injuries}

The higher susceptibility of the myocardium to I/R in COexposed rats was notably characterized by higher propensity to arrhythmic events at the onset of reperfusion. Higher arrhythmic score and higher occurrence of sustained VF (54 vs. 9\%) were evidenced. Arrhythmias, and more particularly sustained $\mathrm{VF}$, are the most dangerous consequences of myocardial I/R, since they induce an impairment of blood circulation and ultimately lead to sudden cardiac death. Sheps et al. $(31,32)$ have already highlighted the proarrhythmic effect of $\mathrm{CO}$ exposure (1 day at 100 or $200 \mathrm{ppm})$ in patients with documented coronary artery diseases. However, as mentioned above, in our model, no difference of carboxyhemoglobin was reported between $\mathrm{Ctrl}$ and $\mathrm{CO}$ rats 
A
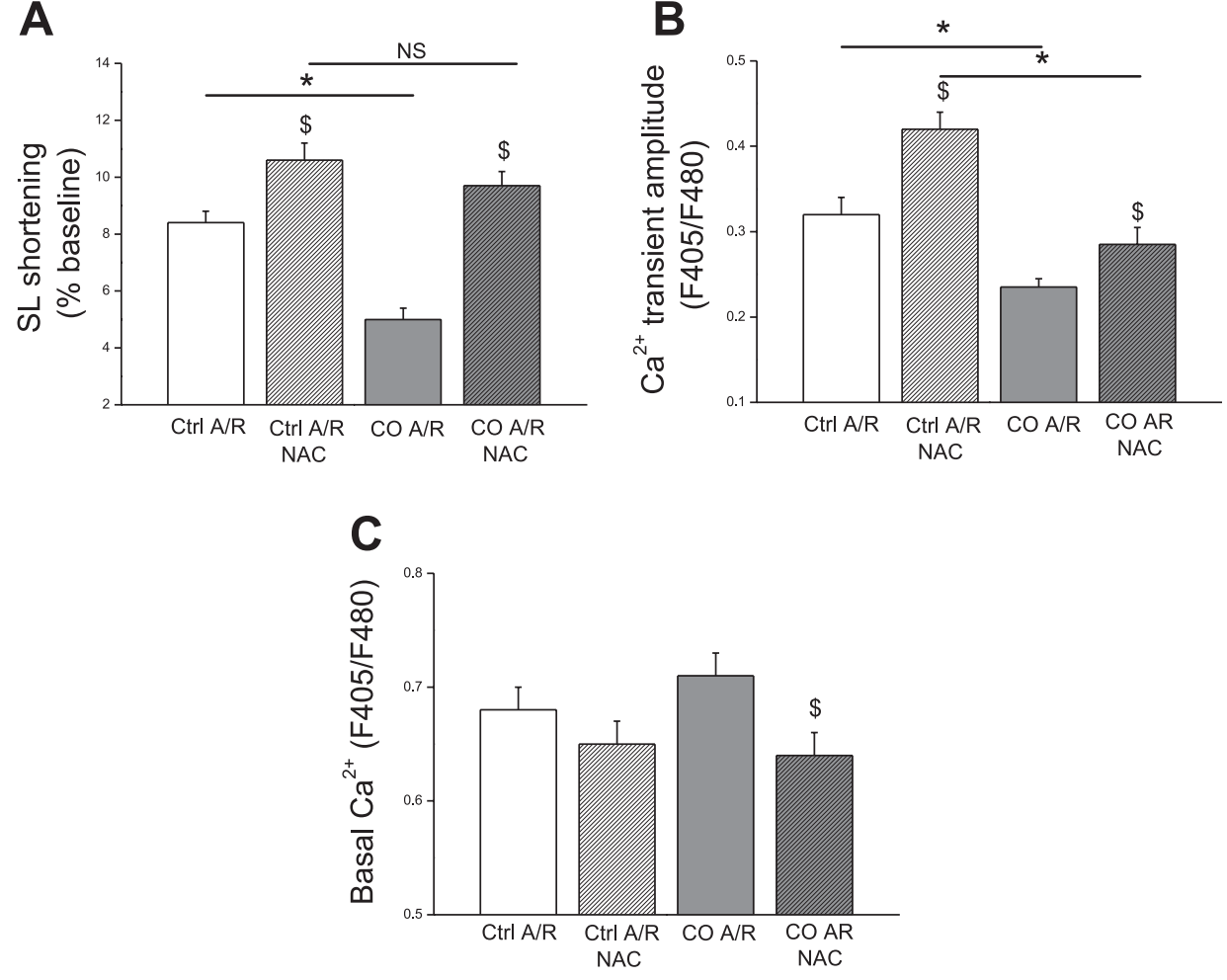

Fig. 5. Effects of $N$-acetylcystein (NAC) incubation on the sensitivity to A/R of cardiomyocytes from $\mathrm{Ctrl}$ and $\mathrm{CO}$ rats. A: contraction of intact myocytes, measured by SL shortening. SL shortening is presented as a mean of the percentage of shortening \pm SE. $B$ and $C$ : $\mathrm{Ca}^{2+}$ transients $(B)$ and $(C)$ diastolic $\mathrm{Ca}^{2+}(C)$ in intact myocytes. $\mathrm{Ca}^{2+}$ transients and diastolic $\mathrm{Ca}^{2+}$ are presented as means \pm SE $[n=4$ rats/group, 2-way ANOVA; $P<$ 0.05 , with NAC vs. without NAC (\$) and Ctrl vs. $\mathrm{CO}$ rats $(*)]$. at the time of the $\mathrm{I} / \mathrm{R}$ procedure, avoiding then the acute effects of $\mathrm{CO}$ on the myocardium. In $\mathrm{CO}$ rats, the higher sensitivity of the myocardium was also characterized by an impairment of postischemic recovery of myocardial function. This could be related to the significantly impaired cellular contractile function observed, consecutive to A/R, on isolated cardiomyocytes of $\mathrm{CO}$ rats compared with Ctrl rats. This result suggests that cardiomyocyte damages lead to a reduced postischemic recovery of cardiac function. It seems, however, that the main factor involved in the explanation of this result was that $\mathrm{CO}$ pollution is associated, in our model, with a marked increase of I/R-induced cardiac cell death. I/R injuries, including cardiomyocyte impairments as well as arrhythmic events, were mainly explained, in past literature, by increased oxidative stress and $\mathrm{Ca}^{2+}$ handling alteration $(25,41)$.

\section{Implication of $\mathrm{Ca}^{2+}$ and Oxidative Stress}

The increased sensitivity to I/R of the myocardium after $\mathrm{CO}$ exposure was characterized by the increase of arrhythmic events, increased functional disturbances, and cell death. The cellular mechanisms underlying theses aspects of the reperfusion syndrome may involve impairments of $\mathrm{Ca}^{2+}$ handling or overproduction of oxygen-derived free radicals. In a recent study, we have shown that $\mathrm{CO}$ pollution by itself initiates a pathological phenotype of the cardiomyocytes involving a profound remodeling of the excitationcontraction coupling through $\mathrm{Ca}^{2+}$-handling alteration (2), which was confirmed in the present work. This remodeling was characterized by an impairment of cardiomyocyte shortening that was not observed at the whole heart level. This phenomenon, which has already been reported by our team, may involve compensatory mechanisms (2) that remain to be investigated. The cardiomyocytes also exhibit an increase in diastolic $\mathrm{Ca}^{2+}$ resulting from an altered $\mathrm{Ca}^{2+}$ reuptake in the sarcoplasmic reticulum (SR) due to a decreased sarco(endo)plasmic reticulum $\mathrm{Ca}^{2+}$-ATPase (SERCA) 2a expression and also potentially from a $\mathrm{Ca}^{2+}$ leak from the SR through the ryanodine receptors (2). Alterations of $\mathrm{Ca}^{2+}$ handling may be involved in cardiomyocyte dysfunction and ultimately in cell death during $\mathrm{I} / \mathrm{R}(1,33,38)$. It is therefore very likely that these alterations, associated with $\mathrm{CO}$ exposure, increase the severity of cardiomyocytes and whole heart injuries related to I/R. Indeed, in our study, at the whole heart level, $\mathrm{CO}$ exposure increases cardiomyocyte death after I/R. Considering only viable myocytes, we report here that SL shortening and $\mathrm{Ca}^{2+}$ handling are altered by $\mathrm{A} / \mathrm{R}$ to the same extent in both $\mathrm{Ctrl}$ and $\mathrm{CO}$ rats, resulting therefore in more pronounced dysfunctions in $\mathrm{CO}$ rats compared with $\mathrm{Ctrl}$ rats. Therefore, it seems that $\mathrm{Ca}^{2+}$ handling in viable cardiomyocytes was not more impaired by $\mathrm{A} / \mathrm{R}$ in $\mathrm{CO}$ rats, but that the lower amplitude of $\mathrm{Ca}^{2+}$ transient reported in this population following $\mathrm{A} / \mathrm{R}$ was the result of prolonged $\mathrm{CO}$ exposure-induced phenotypical changes. Consequently, a major finding of the present study was that the impaired $\mathrm{Ca}^{2+}$ handling observed before to $\mathrm{A} / \mathrm{R}$ is a key factor in the development of functional impairments and arrhythmic events observed at the onset of reperfusion in $\mathrm{CO}$ rats and is therefore a candidate to explain higher sensitivity of $\mathrm{CO}$ rat myocardium to I/R.

The essential role of oxidative stress in the pathogenesis of myocardial I/R injury has been largely reported $(16,30,41)$. Indeed, exacerbated oxidative stress during $\mathrm{I} / \mathrm{R}$ is a key factor in the worsening of postischemic arrhythmias, cardiac dysfunction, and irreversible cardiomyocyte damages $(16,17,25,41)$. Oxidative stress is defined as an imbalance between the pro- 


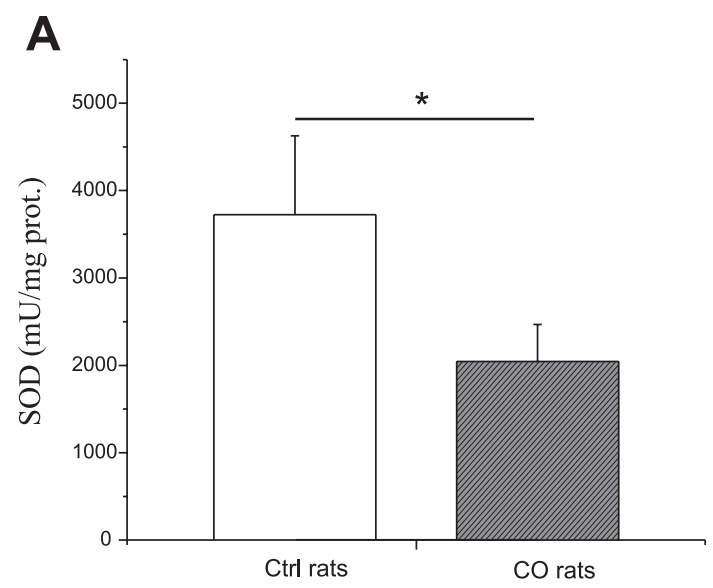

B

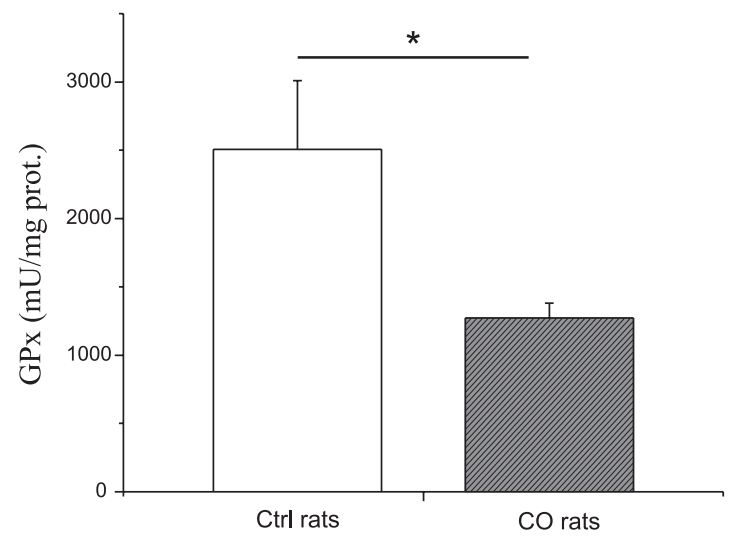

C

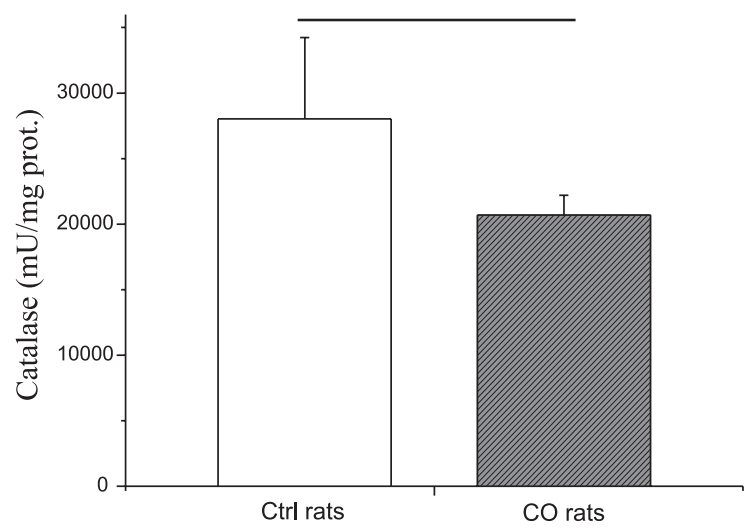

Fig. 6. Effects of $\mathrm{CO}$ exposure on superoxide dismutase (SOD, $A$ ), glutathione peroxidase $(\mathrm{GPx}, B)$, and catalase $(C)$ activities expressed in $\mathrm{mU} / \mathrm{mg}$ protein. Data are presented as means $\pm \mathrm{SE}(n=6$ rats/group, 1 -way ANOVA, $* P<$ 0.05 , Ctrl vs. CO rats)

duction of reactive oxygen species and biological antioxidant systems that are involved in the detoxification of reactive intermediates. An important result of our study is the impaired enzymatic antioxidant status of the myocardium, including a major decreased activity of SOD $(-45 \%)$, GPx $(-49 \%)$, and catalase $(-26 \%$, not statistically significant). We previously discussed the potential role of altered redox status of the myocardium to explain the effects of prolonged exposure to $\mathrm{CO}$ on excitation-contraction coupling (2). Indeed, since proteins involved in $\mathrm{Ca}^{2+}$ handling are potential targets for redox alterations, decrease of antioxidant defenses associated with the increased activity of thioredoxin reductase observed in our previous study (2) confirmed a CO-induced oxidative stress. Therefore, those alterations of enzymatic antioxidant defense could play a major role in phenotypical changes of $\mathrm{CO}$ exposed rat myocardium, mainly affecting $\mathrm{Ca}^{2+}$ homeostasy. Besides, SOD prevents changes in myocardial function, and $\mathrm{Ca}^{2+}$ homeostasis in isolated hearts subjected to I/R (27), catalase, and GPx plays a major role in protecting the myocardium from I/R injury (16). We have observed an increase in TBARS production, used as a marker of lipid peroxidation, and therefore oxidative stress, in CO-exposed rats following I/R. Therefore, we can postulate that the lower enzymatic antioxidant defense that was observed consecutively to $\mathrm{CO}$ exposure could contribute to the increased sensitivity of the myocardium to $\mathrm{I} / \mathrm{R}$ damages. To prevent oxidative stress-induced alterations, an acute antioxidant strategy, using a nonspecific antioxidant (NAC), was performed during cellular A/R. This acute antioxidant strategy was found able to prevent the deleterious effects of $\mathrm{CO}$ exposure on SL shortening during A/R. This result highlights the implication of an increased cardiac oxidative stress in our model of CO-exposed rats. However, the deleterious effects of $\mathrm{CO}$ exposure on $\mathrm{Ca}^{2+}$ transient were not prevented by this acute antioxidant strategy. This observation is not surprising, since prolonged exposure to $\mathrm{CO}$ pollution results in phenotypical remodeling of $\mathrm{Ca}^{2+}$-handling proteins, such as decreased SERCA2a expression (2). This profound remodeling of the $\mathrm{Ca}^{2+}$-handling phenotype, which was reported in $\mathrm{CO}$ rat myocardium, could not be reversed by such an acute antioxidant strategy. Therefore, chronic antioxidant therapy, notably by preventing myocardial phenotypical changes, could be a promising strategy for protecting the heart against the deleterious effects of chronic $\mathrm{CO}$ exposure on myocardial sensitivity to $\mathrm{I} / \mathrm{R}$.

In conclusion, this study shows that chronic exposure to $\mathrm{CO}$ consistent with air pollution from the urban type significantly increases the effects of a myocardial infarction in rats and could be considered as a major health risk. Indeed, the World Health Organization estimates that air pollution is responsible for 800,000 premature deaths worldwide each year, and, particularly, exposure to air pollution increases the risk of mortality from cardiovascular disease by $76 \%$ (23). Among the numerous pollutants, $\mathrm{CO}$ has been described as one of the main pollutants responsible for the development of cardiovascular diseases $(9,35)$. Prolonged $\mathrm{CO}$ exposure worsens I/R-linked cardiac injuries and therefore provides an experimental rationale to explain the increased risk of cardiac mortality observed in exposed populations. In summary, prolonged $\mathrm{CO}$ exposureinduced cardiac phenotypical changes, such as an imbalance in the cardiomyocyte oxidant status and an impairment of $\mathrm{Ca}^{2+}$ handling, are likely to predispose the heart to I/R injuries.

\section{GRANTS}

This work was funded by a French National Research Agency grant (COMYOCARD)

\section{DISCLOSURES}

No competing financial interests exist. 


\section{REFERENCES}

1. Abdallah Y, Gkatzoflia A, Gligorievski D, Kasseckert S, Euler G, Schluter KD, Schafer M, Piper HM, Schafer C. Insulin protects cardiomyocytes against reoxygenation-induced hypercontracture by a survival pathway targeting SR Ca2+ storage. Cardiovasc Res 70: 346-353, 2006.

2. Andre L, Boissiere J, Reboul C, Perrier P, Zalvidea S, Thireau J, Meyer G, Bideaux P, Obert P, Cazorla O, Richard S. Carbon monoxide pollution promotes cardiac remodeling and ventricular arrythmia in healthy rats. Am J Respir Crit Care Med In press

3. Bagul A, Hosgood SA, Kaushik M, Nicholson ML. Carbon monoxide protects against ischemia-reperfusion injury in an experimental model of controlled nonheartbeating donor kidney. Transplantation 85: 576-581, 2008.

4. Bak I, Papp G, Turoczi T, Varga E, Szendrei L, Vecsernyes M, Joo F, Tosaki A. The role of heme oxygenase-related carbon monoxide and ventricular fibrillation in ischemic/reperfused hearts. Free Radic Biol Med 33: 639-648, 2002

5. Bak I, Szendrei L, Turoczi T, Papp G, Joo F, Das DK, de Leiris J, Der P, Juhasz B, Varga E, Bacskay I, Balla J, Kovacs P, Tosaki A. Heme oxygenase-1-related carbon monoxide production and ventricular fibrillation in isolated ischemic/reperfused mouse myocardium. FASEB $J$ 17: 2133-2135, 2003.

6. Bak I, Varadi J, Nagy N, Vecsernyes M, Tosaki A. The role of exogenous carbon monoxide in the recovery of post-ischemic cardiac function in buffer perfused isolated rat hearts. Cell Mol Biol (Noisy-legrand) 51: 453-459, 2005 .

7. Barnett AG, Williams GM, Schwartz J, Best TL, Neller AH, Petroeschevsky AL, Simpson RW. The effects of air pollution on hospitalizations for cardiovascular disease in elderly people in Australian and New Zealand cities. Environ Health Perspect 114: 1018-1023, 2006

8. Beers RF Jr, Sizer IW. A spectrophotometric method for measuring the breakdown of hydrogen peroxide by catalase. J Biol Chem 195: 133-140, 1952

9. Bell ML, Peng RD, Dominici F, Samet JM. Emergency Hospital Admissions for Cardiovascular Diseases and Ambient Levels of Carbon Monoxide. Results for 126 United States Urban Counties, 1999-2005. Circulation 120: 949-955, 2009.

10. Bevan MA, Proctor CJ, Baker-Rogers J, Warren ND. Exposure to carbon monoxide, respirable syspended particulates, and volatile organic compounds while commuting by bicycle. Environ Sci Technol 25: $788-$ $779,1991$.

11. Bhatnagar A. Environmental cardiology: studying mechanistic links between pollution and heart disease. Circ Res 99: 692-705, 2006.

12. Brook RD, Franklin B, Cascio W, Hong Y, Howard G, Lipsett M, Luepker R, Mittleman M, Samet J, Smith SC Jr, Tager I. Air pollution and cardiovascular disease: a statement for healthcare professionals from the Expert Panel on Population and Prevention Science of the American Heart Association. Circulation 109: 2655-2671, 2004.

13. Burnett RT, Cakmak S, Brook JR, Krewski D. The role of particulate size and chemistry in the association between summertime ambient air pollution and hospitalization for cardiorespiratory diseases. Environ Health Perspect 105: 614-620, 1997.

14. Bye A, Sorhaug S, Ceci M, Hoydal MA, Stolen T, Heinrich G, Tjonna AE, Najjar SM, Nilsen OG, Catalucci D, Grimaldi S, Contu R, Steinshamn S, Condorelli G, Smith GL, Ellingsen O, Waldum H, Wisloff U. Carbon monoxide levels experienced by heavy smokers impair aerobic capacity and cardiac contractility and induce pathological hypertrophy. Inhal Toxicol 20: 635-646, 2008.

15. Chen TM, Shofer S, Gokhale J, Kuschner WG. Outdoor air pollution: overview and historical perspective. Am J Med Sci 333: 230-234, 2007.

16. Dhalla NS, Temsah RM, Netticadan T. Role of oxidative stress in cardiovascular diseases. J Hypertens 18: 655-673, 2000.

17. Dumitrescu C, Biondi R, Xia Y, Cardounel AJ, Druhan LJ, Ambrosio G, Zweier JL. Myocardial ischemia results in tetrahydrobiopterin (BH4) oxidation with impaired endothelial function ameliorated by BH4. Proc Natl Acad Sci USA 104: 15081-15086, 2007.

18. Flohe L, Gunzler WA. Assays of glutathione peroxidase. Methods Enzymol 105: 114-121, 1984.

19. Fujimoto H, Ohno M, Ayabe S, Kobayashi H, Ishizaka N, Kimura H, Yoshida K, Nagai R. Carbon monoxide protects against cardiac ischemia-reperfusion injury in vivo via MAPK and Akt-eNOS pathways. Arterioscler Thromb Vasc Biol 24: 1848-1853, 2004.
20. Li Volti G, Rodella LF, Di Giacomo C, Rezzani R, Bianchi R, Borsani E Gazzolo D, Motterlini R. Role of carbon monoxide and biliverdin in rena ischemia/reperfusion injury. Nephron Exp Nephrol 104: e135-e139, 2006.

21. Lowry OH, Rosebrough NJ, Farr AL, Randall RJ. Protein measurement with the Folin phenol reagent. J Biol Chem 193: 265-275, 1951.

22. Marklund S. Spectrophotometric study of spontaneous disproportionation of superoxide anion radical and sensitive direct assay for superoxide dismutase. J Biol Chem 251: 7504-7507, 1976

23. Miller KA, Siscovick DS, Sheppard L, Shepherd K, Sullivan JH, Anderson GL, Kaufman JD. Long-term exposure to air pollution and incidence of cardiovascular events in women. N Engl J Med 356: 447-458, 2007

24. Mou YA, Reboul C, Andre L, Lacampagne A, Cazorla O. Late exercise training improves non-uniformity of transmural myocardial function in rats with ischaemic heart failure. Cardiovasc Res 81: 555-564, 2009.

25. Murphy E, Steenbergen C. Mechanisms underlying acute protection from cardiac ischemia-reperfusion injury. Physiol Rev 88: 581-609, 2008

26. Nakao A, Neto JS, Kanno S, Stolz DB, Kimizuka K, Liu F, Bach FH, Billiar TR, Choi AM, Otterbein LE, Murase N. Protection against ischemia/reperfusion injury in cardiac and renal transplantation with carbon monoxide, biliverdin and both. Am J Transplant 5: 282-291, 2005

27. Netticadan $\mathbf{T}$, Temsah $\mathbf{R}$, Osada $\mathbf{M}$, Dhalla NS. Status of $\mathrm{Ca}^{2+}$ calmodulin protein kinase phosphorylation of cardiac SR proteins in ischemia-reperfusion. Am J Physiol Cell Physiol 277: C384-C391, 1999.

28. Ruiz-Meana M, Garcia-Dorado D. Translational cardiovascular medicine (II) Pathophysiology of ischemia-reperfusion injury: new therapeutic options for acute myocardial infarction. Rev Esp Cardiol 62: 199-209, 2009

29. Samoli E, Touloumi G, Schwartz J, Anderson HR, Schindler C, Forsberg B, Vigotti MA, Vonk J, Kosnik M, Skorkovsky J, Katsouyanni K. Short-term effects of carbon monoxide on mortality: an analysis within the APHEA project. Environ Health Perspect 115: 1578-1583, 2007.

30. Schulz R, Kelm M, Heusch G. Nitric oxide in myocardial ischemia reperfusion injury. Cardiovasc Res 61: 402-413, 2004.

31. Sheps DS, Herbst MC, Hinderliter AL, Adams KF, Ekelund LG, O'Neil JJ, Goldstein GM, Bromberg PA, Ballenger M, Davis SM. Effects of 4 percent and 6 percent carboxyhemoglobin on arrhythmia production in patients with coronary artery disease. Res Rep Health Eff Inst 1-58, 1991.

32. Sheps DS, Herbst MC, Hinderliter AL, Adams KF, Ekelund LG O'Neil JJ, Goldstein GM, Bromberg PA, Dalton JL, Ballenger MN. Production of arrhythmias by elevated carboxyhemoglobin in patients with coronary artery disease. Ann Intern Med 113: 343-351, 1990.

33. Siegmund B, Schlack W, Ladilov YV, Balser C, Piper HM. Halothane protects cardiomyocytes against reoxygenation-induced hypercontracture. Circulation 96: 4372-4379, 1997

34. Stern FB, Halperin WE, Hornung RW, Ringenburg VL, McCammon CS. Heart disease mortality among bridge and tunnel officers exposed to carbon monoxide. Am J Epidemiol 128: 1276-1288, 1988.

35. Stieb DM, Szyszkowicz M, Rowe BH, Leech JA. Air pollution and emergency department visits for cardiac and respiratory conditions: a multi-city time-series analysis (Abstract). Environ Health 8: 25, 2009.

36. Szabo ME, Gallyas E, Bak I, Rakotovao A, Boucher F, de Leiris J, Nagy N, Varga E, Tosaki A. Heme oxygenase-1-related carbon monoxide and flavonoids in ischemic/reperfused rat retina. Invest Ophthalmol Vis Sci 45: 3727-3732, 2004.

37. Tanguy S, Boucher F, Besse S, Ducros V, Favier A, de Leiris J. Trace elements and cardioprotection: increasing endogenous glutathione peroxidase activity by oral selenium supplementation in rats limits reperfusioninduced arrhythmias. J Trace Elem Med Biol 12: 28-38, 1998.

38. Venetucci LA, Trafford AW, O'Neill SC, Eisner DA. The sarcoplasmic reticulum and arrhythmogenic calcium release. Cardiovasc Res 77: 285 292, 2008.

39. Walker MJ, Curtis MJ, Hearse DJ, Campbell RW, Janse MJ, Yellon DM, Cobbe SM, Coker SJ, Harness JB, Harron DW. The Lambeth Conventions: guidelines for the study of arrhythmias in ischaemia infarction, and reperfusion. Cardiovasc Res 22: 447-455, 1988

40. Wright GR, Jewczyk S, Onrot J, Tomlinson P, Shephard RJ. Carbon monoxide in the urban atmosphere: hazards to the pedestrian and the street-worker. Arch Environ Health 30: 123-129, 1975.

41. Zhao X, Chen YR, He G, Zhang A, Druhan LJ, Strauch AR, Zweier JL Endothelial nitric oxide synthase (NOS3) knockout decreases NOS2 induction, limiting hyperoxygenation and conferring protection in the postischemic heart. Am J Physiol Heart Circ Physiol 292: H1541-H1550, 2007. 